\title{
Synthesis, Characterization and Application of Poly(4-Methyl Vinylpyridinium Hydroxide)/SBA-15 Composite as a Highly Active Heterogeneous Basic Catalyst for the Knoevenagel Reaction
}

\author{
Roozbeh Javad Kalbasi, ${ }^{*}$ Majid Kolahdoozan, ${ }^{*}$ Ahmadreza Massah, and Keinaz Shahabian \\ Department of Chemistry, Islamic Azad University, Shahreza Branch, 311-86145, Shahreza, Isfahan, Iran \\ *E-mail: rkalbasi@iaush.ac.ir (R.J.K.),kolahdoozan@iaush.ac.ir (M.K.) \\ Received June 18, 2010, Accepted July 30, 2010
}

\begin{abstract}
In this paper poly (4-methyl vinylpyridinium hydroxide)/SBA-15 composite was prepared as a highly efficient heterogeneous basic catalyst by in situ polymerization method for the first time. It was characterized by XRD, FT-IR, BET, TGA, SEM and back titration using $\mathrm{NaOH}$. This catalyst exhibited the excellent catalytic activities for the Knoevenagel condensation of various aldehydes with ethyl cyanoacetate. Over this catalyst, $\alpha, \beta$-unsaturated carbonyl compounds were obtained in the reasonable yield at $95^{\circ} \mathrm{C}$ in $10-30 \mathrm{~min}$ in $\mathrm{H}_{2} \mathrm{O}$ as a solvent with a $100 \%$ selectivity to the condensation products. Catalyst could be easily recycled after the reaction and it could be reused without the significant loss of activity/selectivity performance. No by-product formation, high yields, short reaction times, mild reaction conditions and operational simplicity with reusability of the catalyst were the salient features of the present synthetic protocol. Presence of $\mathrm{H}_{2} \mathrm{O}$ as a solvent was also recognized as a "green method".
\end{abstract}

Key Words: Knoevenagel condensation, Ethyl cyanoacetate, P4MVPH/SBA-15, Green method, $\mathrm{H}_{2} \mathrm{O}$

\section{Introduction}

The Knoevenagel condensation reaction was well known for its vast potential for the synthesis of $\alpha, \beta$-unsaturated carbonyl compounds from active methylene and carbonyl compounds for the preparation of important intermediates in pharmaceutical industry and was often used as a test reaction for probing the activity of various solid base catalysts. ${ }^{1-6}$ In fact, reacting benzaldehyde with the compounds containing active methylene groups with different $\mathrm{p} K_{\mathrm{a}}$ values, such as ethyl cyanoacetate $\left(\mathrm{p} K_{\mathrm{a}} \leq 9\right)$ or ethyl acetoacetate $\left(\mathrm{p} K_{\mathrm{a}} \leq 10.7\right)$ made it possible to evaluate the basic strength of a catalyst. The catalysts traditionally used were ammonia, primary or secondary amines and their salts. ${ }^{7}$ A wide array of catalysts, such as $\mathrm{TiCl}_{4},{ }^{8} \mathrm{AlPO}_{4^{-}}$ $\mathrm{Al}_{2} \mathrm{O}_{3},{ }^{9} \mathrm{ZnCl}_{2},{ }^{10} \mathrm{Na}_{2} \mathrm{CaP}_{2} \mathrm{O}_{7},{ }^{11}$ chitosan, ${ }^{12}$ ionic liquids containing imidazole ${ }^{13}$ or guanidinium group ${ }^{14}$ had been utilized to catalyze this reaction, each affording variable yields of $\alpha, \beta$ unsaturated carbonyl compounds in solution or under solventfree conditions. But there were many disadvantages in these catalysts. For example, when using the Lewis acidic catalysts, $\mathrm{TiCl}_{4}$ and $\mathrm{ZnCl}_{2}$, the reaction conditions should be carried out in dry media. In addition, these catalysts could not be stabilized and reused because of the water made from the Knoevenagel reaction itself. For chitosan and ionic liquids containing imidazole or guanidinium group, the reaction must be heated and it takes more than $2 \mathrm{~h}$.

Nowadays there is an urgent need for developing green chemistry processes, in where the use of noxious substance and the generation of waste can be avoided. Environmentally and economically, using aqueous media for performing organic reactions had attracted considerable interest because water is considered to be the most environmentally acceptable, safe and inexpensive solvent. Consequently, it was important to carry out organic reactions in water instead of volatile solvent for the environmental and economic reasons. In some approaches Knoevenagel condensation reaction could be performed in water. $^{15-17}$

The development of heterogeneous basic catalysts was an essential requirement for sustainable chemistry. ${ }^{18}$ Using solid catalysts instead of stoichiometric with amount of strong soluble bases, it is seen the following items:

1. The overall atom efficiency of reactions is improved.

2. Processes were simplified.

3. The turn-over-number of the catalyst was increased.

4. The volume of waste was significantly reduced and product work-up becomes easier, if necessary at all.

Comparing the broad application of solid acid catalysts, less attention has been considerably paid to the development of solid basic catalysts. ${ }^{19}$ Typically organic bases immobilized on different supports had been used as the catalytic materials. ${ }^{20,21}$ Progress had predominately been limited because of the active material leaching from the various types of the applied support. ${ }^{21,22}$ Other solid bases, such as layered double hydroxides or ion exchanged zeolites were either very active when fresh, but it suffered from severe and rapid deactivation, ${ }^{23}$ or their initial activity was rather low. ${ }^{24}$

Surface-modified mesoporous materials with various active sites had been extensively investigated in recent years because functional modification permits tailoring the surface properties for numerous potential applications in the fields of heterogeneous catalysis and adsorption-separation. Typically the modification of mesoporous materials utilizes two general approaches: (1) the direct synthesis wherein a silane containing the desired functional group was added to the synthesis mixture and the functional group was incorporated during synthesis, and (2) post-synthetic grafting, i.e. the functional group was incorporated after removing the surfactant/polymer template from the mesopores. 
Among the known mesoporous materials, stable hydrothermal SBA- $15^{25,26}$ was a highly ordered mesoporous silica with two-dimensional p6mm symmetry, which possessed hexagonal arrays of uniform pores, large special surface area and high pore volume which make these materials the excellent candidates for supporting the active functional groups such as functional polymers. Although SBA-15 usually suffered from an inherent lack of active sites which are necessary for catalysis and adsorption, its surface modification had become as the paramount for its industrial application.

Functional polymers could be very efficient catalyst supports, since they provided the stabilizing steric bulk of their framework and several binding sites for simultaneous interactions with the particles and the substrates. ${ }^{27}$ Poly (4-vinylpyridine) (P4VP) was particularly attractive because of the strong affinity of the pyridyl group for metallic nanoparticles and because of its ability for interacting with polar species like quinoline through hydrogen bonding. It was easily protonated $\left(\mathrm{p} K_{\mathrm{a}}=7.4\right)$ providing materials capable of undergoing strong electrostatic interactions with charged species may lead to an enhanced catalytic activity. ${ }^{28}$ P4VP could be quaternized with different kinds of alkyl halides and acted as a catalyst with high catalytic activity in organic reactions. ${ }^{29}$

The lack of examples of polymers applied in the field of heterogeneous organocatalysis may be generated from two drawbacks for most polymers: their low thermal stability which prevented them from being applied under standard reaction conditions and/or their low mechanical stability, which prevented their texturation at nanoscale known as an advantageous for catalytic applications. ${ }^{30}$ One way for overcoming these drawbacks was to use of polymer-inorganic hybrid instead of polymeric materials.

In this paper, it was attempted to report the synthesis of poly (4-methyl vinylpyridinium hydroxide) (P4MVPH) supported on SBA-15 by polymerization of 4-vinylpyridine (4VP) in the presence of SBA-15 and subsequent modification of the resulting polymers functional groups. The large surface of SBA-15 causes this novel compound to act as an efficient basic catalyst. The basic catalytic activity of this novel organic-inorganic hybrid was tested for Knoevenagel condensation reaction in water as a solvent.

Green media for this reaction, catalyst reusability and simple work-up of the product were the main advantages for this polymer material supported on the inorganic surface.

\section{Experimental Methods}

Chemicals supply. All chemicals were obtained from SigmaAldrich, Merck and used without further purification.

Instruments and characterization. The catalyst was characterized by X-ray diffraction (Bruker D8ADVANCE, $\mathrm{Cu} \mathrm{K} \alpha$ radiation), FT-IR spectroscopy (Nicolet 400D in $\mathrm{KBr}$ matrix in the range of $4000-400 \mathrm{~cm}^{-1}$ ), BET specific surface areas and BJH pore size distribution (Series BEL SORP 18, at $77 \mathrm{~K}$ ), thermal analyzer TGA (Setaram Labsys TG (STA) in temperature $30-700^{\circ} \mathrm{C}$ and heating rate of $10{ }^{\circ} \mathrm{C} / \mathrm{min}$ in $\mathrm{N}_{2}$ atmosphere) and SEM (Philips, XL30, SE detector).

The products were characterized by ${ }^{1} \mathrm{H}$ and ${ }^{13} \mathrm{C}$ NMR spectra
(Bruker DRX-500 Avance spectrometer at 500.13 and 125.47 $\mathrm{MHz}$, respectively), GC (Agilent 6820 equipped with a FID detector) and GC-MS (Agilent 6890). Melting points were measured on an Electrothermal 9100 apparatus and they were uncorrected. All the products were known compounds and they were characterized by IR, ${ }^{1} \mathrm{H}$ NMR and ${ }^{13} \mathrm{C}$ NMR. All melting points are compared satisfactorily with those reported in the literature.

\section{Catalyst synthesis.}

Synthesis of SBA-15: Mesoporous silica SBA-15 was prepared by the method recently described in the literature. ${ }^{31} \mathrm{Plu}-$ ronic $\mathrm{P} 123$ (2 g) were dissolved at room temperature in $\mathrm{H}_{3} \mathrm{PO}_{4}$ $(4.16 \mathrm{~mL} 85 \%)$ and deionized water $(75.37 \mathrm{~mL})$, then TEOS $(4.58 \mathrm{~mL})$ was added to this solution and the synthesis was carried out by stirring at $35^{\circ} \mathrm{C}$ for $24 \mathrm{~h}$ in sealed Teflon breakers and subsequently placed at $100{ }^{\circ} \mathrm{C}$ for $24 \mathrm{~h}$. Then the solution was filtered, washed with deionized water and finally dried at $95^{\circ} \mathrm{C}$ for $12 \mathrm{~h}$ in air. Template removal was performed by calcinations in air using two successive steps, first heating at $250{ }^{\circ} \mathrm{C}$ for $3 \mathrm{~h}$ and second at $550{ }^{\circ} \mathrm{C}$ for $4 \mathrm{~h}$.

Synthesis of poly (4-methyl vinylpyridinium hydroxide)/ SBA-15: P4MVPH/SBA-15 composite was synthesized in three steps (Scheme 1):

At first, 4-vinyl pyridine ( $2 \mathrm{~mL}, 0.019 \mathrm{~mol})$, benzoylperoxide $(0.132 \mathrm{~g})$, SBA-15 $(2 \mathrm{~g})$ and THF $(20 \mathrm{~mL})$ were added into a $50 \mathrm{~mL}$ round-bottomed flask. The solution was stirred with magnetic stirrer and refluxed for $6 \mathrm{~h}$ at $65^{\circ} \mathrm{C}$. Then the solution was filtered and washed with THF $(2 \times 10 \mathrm{~mL})$. The white precipitate was dried in air overnight to yield $3.4 \mathrm{~g}$ poly 4-vinylpyridine/SBA-15 (P4VP/SBA-15).

In the second step, obtained P4VP/SBA-15, $\mathrm{CH}_{3} \mathrm{I}(2.9 \mathrm{~mL})$ and $\mathrm{CH}_{2} \mathrm{Cl}_{2}(20 \mathrm{~mL})$ were added to a $50 \mathrm{~mL}$ round-bottomed flask. The solution was stirred with magnetic stirrer and refluxed for $6 \mathrm{~h}$ at $40{ }^{\circ} \mathrm{C}$. This mixture was filtered and washed with $\mathrm{CH}_{2} \mathrm{Cl}_{2}(2 \times 10 \mathrm{~mL})$ and the yellow precipitate was dried in air to yield $4.2 \mathrm{~g}$ poly 4-methyl vinylpyridinium iodide/SBA-15 (P4MVPI/SBA-15). Amount of iodide in P4MVPI/SBA-15

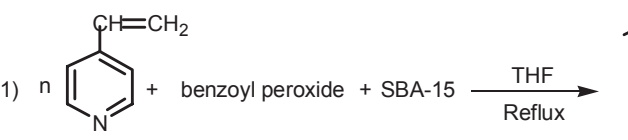

$$
\text { 1) }
$$$$
N \text { Reflux }
$$

2) $\mathrm{P} 4 \mathrm{VP} / \mathrm{SBA}-15+\mathrm{CH}_{3} \mathrm{I}$

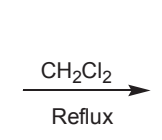

3)

P4MVPI/SBA-15 $+\mathrm{NaOH}$

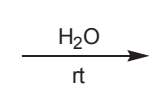
SBA-15
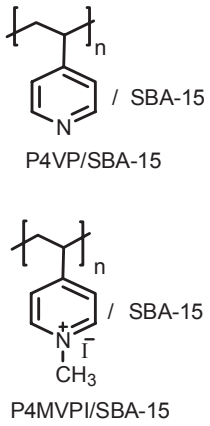

Scheme 1. Preparation of P4MVPH/SBA-15 
was determined by ICP-MS (inductively coupled plasma mass spectrometry). Iodide content of P4MVPI/SBA-15 was 1.5 mmol g ${ }^{-1}$.

In the third step, a solution of $\mathrm{NaOH}(0.89 \mathrm{~g} \mathrm{NaOH}$ in $40 \mathrm{~mL}$ $\mathrm{H}_{2} \mathrm{O}$ ) was added to the obtained P4MVPI/SBA-15 at room temperature. The mixture was stirred for $12 \mathrm{~h}$. Then it was filtered and washed sequentially with deionized water for removing the excess $\mathrm{OH}^{-}$and then dried in $50^{\circ} \mathrm{C}$ to yield P4MVPH/ SBA-15 composite.

Hydroxide content of P4MVPH/SBA-15 composite was estimated by back titration using $\mathrm{NaOH}(0.2 \mathrm{~N}) .10 \mathrm{~mL}$ of $\mathrm{HCl}$ was added to $0.1 \mathrm{~g}$ of this composite and stirred for 30 minutes. The catalyst was removed and washed successively with dionized water. The excess amount of $\mathrm{HCl}$ was titrated with $\mathrm{NaOH}(0.2 \mathrm{~N})$ in the presence of phenol phthalein as indicator. Basic sites content of catalyst was $5.5 \mathrm{mmol} \mathrm{g}^{-1}$.

General procedure for Knoevenagel condensation. In a typical procedure, $50 \mathrm{~mL}$ flask equipped with a magnetic stirrer was charged with aromatic aldehyde ( $2 \mathrm{mmol})$, ethylcyanoacetate ( $2 \mathrm{mmol}, 0.213 \mathrm{~mL}$ ), catalyst (0.12 g, P4MVPH/SBA-15) and $\mathrm{H}_{2} \mathrm{O}(10 \mathrm{~mL})$. The reaction mixture was stirred vigorously at $95{ }^{\circ} \mathrm{C}$ using a magnetic stirrer for 5 - $35 \mathrm{~min}$ (mild stirring rate resulting into relatively low yield). Completion of the reaction was monitored by TLC using $n$-hexane/ethylacetate (16:4) as eluent, and by GC (Agilent $6820 \mathrm{GC}$ ). For the reaction work-up, the mixture was cooled for $10{ }^{\circ} \mathrm{C}$ for the solidification of the product. Water was removed by Buchner filtration and the residual solids were washed with heated ethanol $(5 \mathrm{~mL})$ and recrystallized. The products were identified with ${ }^{1} \mathrm{H} N M R,{ }^{13} \mathrm{C}$ NMR, GC-Mass and FT-IR spectroscopy techniques. Quantitative analyses were conducted with an Agilent $6820 \mathrm{GC}$ equipped with a FID detector. Isolated yield was obtained by using column chromatography with GC yield. Decane was added as an internal standard for GC analysis. The catalyst was recovered and reused in the reaction of ethyl cyanoacetate with benzaldehyde for four times. Additionally by using the reused catalyst, the selectivity $(100 \%$ to $\alpha, \beta$-unsaturated carbonyl compounds) and yield (98\%) were not changed.

Spectral data of the some desired products.

2-Propenoic acid-2-cyano-3-phenyl ethyl ester (Table 6, Entry 1): White crystall solid, mp $49-51{ }^{\circ} \mathrm{C} ;\left(\mathrm{KBr}, \mathrm{cm}^{-1}\right): 1446$, $1606(\mathrm{C}=\mathrm{C}$, aromatic), $1733(\mathrm{C}=\mathrm{O}), 2221(\mathrm{CN}), 2982(\mathrm{CH}, \mathrm{str})$, 3029 (=CH, str), 3069 (CH, str, aromatic); ${ }^{1} \mathrm{H} \mathrm{NMR}(500 \mathrm{MHz}$, $\left.\mathrm{CDCl}_{3}\right) \delta 1.43\left(\mathrm{CH}_{3}, \mathrm{t}, 3 \mathrm{H}, J=7.1 \mathrm{~Hz}\right), 4.42\left(\mathrm{CH}_{2}, \mathrm{q}, 2 \mathrm{H}, J=7.1\right.$ $\mathrm{Hz}$ ) 7.52-7.60 (ArH, m, 3H), $8.02(\mathrm{ArH}, \mathrm{d}, 2 \mathrm{H}, J=7.4 \mathrm{~Hz}), 8.28$ $(=\mathrm{CH}, \mathrm{s}, 1 \mathrm{H}) ;{ }^{13} \mathrm{CNMR}\left(125 \mathrm{MHz}, \mathrm{CDCl}_{3}\right) \delta 14.59\left(\mathrm{CH}_{3}\right), 63.15$ $\left(\mathrm{O}-\mathrm{CH}_{2}\right), 103.49(\mathrm{C}-\mathrm{CN}), 115.90(\mathrm{CN}), 129.71,131.49,131.92$, $133.72,155.44,162.89(\mathrm{C}=\mathrm{O})$.

2-Propenoic acid-2-cyano-3-(2-pyridiny) ethyl ester(Table 6, Entry 2): Dark brown crystall solid, mp $92-94{ }^{\circ} \mathrm{C}$; IR ( $\mathrm{KBr}$, $\left.\mathrm{cm}^{-1}\right): 1467(\mathrm{C}=\mathrm{C}$, aromatic), $1697(\mathrm{C}=\mathrm{O}), 2188(\mathrm{CN}), 2978$ (CH, str.), 3089 (=CH, str.).

2-Propenoic acid-2-cyano-3-(3-methyl phenyl) ethyl ester (Table 6, Entry 3): White crystall solid, $\mathrm{mp} 82-85^{\circ} \mathrm{C}$; IR ( $\mathrm{KBr}$, $\left.\mathrm{cm}^{-1}\right)$ : 1450, $1609(\mathrm{C}=\mathrm{C}$, aromatic), $1728(\mathrm{C}=\mathrm{O}), 2218(\mathrm{CN})$, 2908, 2982 (CH, str), 3022 (=CH, str); ${ }^{1} \mathrm{H}$ NMR (500 MHz, $\left.\mathrm{CDCl}_{3}\right) \delta 1.44\left(\mathrm{CH}_{3}, \mathrm{t}, 3 \mathrm{H}, J=7.1 \mathrm{~Hz}\right), 2.45\left(\mathrm{CH}_{3}, \mathrm{~s}, 3 \mathrm{H}\right), 4.42$ $\left(\mathrm{CH}_{2}, \mathrm{q}, 2 \mathrm{H}, J=7.1 \mathrm{~Hz}\right), 7.39-7.44$ (ArH, m, 2H), 7.81 (ArH, s,
1H), $7.85(\mathrm{ArH}, \mathrm{d}, 1 \mathrm{H}, J=7.3), 8.25(=\mathrm{CH}, \mathrm{s}, 1 \mathrm{H}) ;{ }^{13} \mathrm{C} \mathrm{NMR}$ $\left(125 \mathrm{MHz}, \mathrm{CDCl}_{3}\right) \delta 14.59\left(\mathrm{CH}_{3}\right), 21.71\left(\mathrm{CH}_{3}\right.$, aromatic $), 63.11$ $\left(\mathrm{O}-\mathrm{CH}_{2}\right), 103.12(\mathrm{C}-\mathrm{CN}), 115.97(\mathrm{CN}), 128.66,129.59,131.91$, $132.12,134.64,139.56,155.70,163.04(\mathrm{C}=\mathrm{O})$.

2-Propenoic acid-2-cyano-3-(4-methoxy phenyl) ethyl ester (Table 6, Entry 5): White crystall solid, mp $81-82^{\circ} \mathrm{C}$; IR ( $\mathrm{KBr}$, $\left.\mathrm{cm}^{-1}\right): 1435,1510,1585(\mathrm{C}=\mathrm{C}$, aromatic $), 1722(\mathrm{C}=\mathrm{O}), 2213$ (CN), 2841, 2990 (CH, str.), 3021 (=CH, str.); ${ }^{1} \mathrm{H}$ NMR (500 $\left.\mathrm{MHz}, \mathrm{CDCl}_{3}\right) \delta 1.43\left(\mathrm{CH}_{3}, \mathrm{t}, 3 \mathrm{H}, J=7.1 \mathrm{~Hz}\right), 3.93\left(\mathrm{CH}_{3} \mathrm{O}, \mathrm{s}\right.$, $3 \mathrm{H}), 4.40\left(\mathrm{CH}_{2}, \mathrm{q}, 2 \mathrm{H}, J=7.1 \mathrm{~Hz}\right), 7.03(\mathrm{ArH}, \mathrm{d}, 2 \mathrm{H}, J=8.9$ $\mathrm{Hz}), 8.04(\mathrm{ArH}, \mathrm{d}, 2 \mathrm{H}, J=8.9 \mathrm{~Hz}), 8.21(=\mathrm{CH}, \mathrm{s}, 1 \mathrm{H}) ;{ }^{13} \mathrm{C} \mathrm{NMR}$ $\left(125 \mathrm{MHz}, \mathrm{CDCl}_{3}\right) \delta 14.63\left(\mathrm{CH}_{3}\right), 56.05\left(\mathrm{CH}_{3} \mathrm{O}\right), 62.86\left(\mathrm{O}-\mathrm{CH}_{2}\right)$, $99.84(\mathrm{C}-\mathrm{CN}), 116.65(\mathrm{CN}), 115.20,124.82,134.07,154.82$, $164.22,163.56(\mathrm{C}=\mathrm{O})$.

2-Propenoic acid-3-(2-chloro phenyl)-2-cyano ethyl ester (Table 6, Entry 6): White crystall solid, mp $52-54^{\circ} \mathrm{C}$; IR ( $\mathrm{KBr}$, $\left.\mathrm{cm}^{-1}\right)$ : 1470, $1603(\mathrm{C}=\mathrm{C}$, aromatic $), 1728(\mathrm{C}=\mathrm{O}), 2224(\mathrm{CN})$, 2919 (CH, str.), 2992 (=CH, str.), 3064 (CH, str, aromatic); ${ }^{1} \mathrm{H}$ $\operatorname{NMR}\left(500 \mathrm{MHz}, \mathrm{CDCl}_{3}\right) \delta 1.44\left(\mathrm{CH}_{3}, \mathrm{t}, 3 \mathrm{H}, J=7.2 \mathrm{~Hz}\right), 4.44$ $\left(\mathrm{CH}_{2}, \mathrm{q}, 2 \mathrm{H}, J=7.2 \mathrm{~Hz}\right), 7.43-7.55(\mathrm{ArH}, \mathrm{m}, 3 \mathrm{H}), 8.27$ (ArH, d, $1 \mathrm{H}, J=7.6 \mathrm{~Hz}), 8.72(=\mathrm{CH}, \mathrm{s}, 1 \mathrm{H}) ;{ }^{13} \mathrm{C}$ NMR $(125 \mathrm{MHz}$, $\left.\mathrm{CDCl}_{3}\right) \delta 14.56\left(\mathrm{CH}_{3}\right), 63.38\left(\mathrm{O}-\mathrm{CH}_{2}\right), 106.64(\mathrm{C}-\mathrm{CN}), 115.24$ (CN), 127.89, 130.31, 130.77, 134.09, 136.87, 151.59, 162.24 $(\mathrm{C}=\mathrm{O})$.

2-Propenoic acid-2-cyano-3-(4-nitro phenyl) ethyl ester (Table 6, Entry 7): Yellow crystall solid, mp $165^{\circ} \mathrm{C}$; IR ( $\mathrm{KBr}$, $\left.\mathrm{cm}^{-1}\right): 1516(\mathrm{C}=\mathrm{C}$, aromatic $), 1722(\mathrm{C}=\mathrm{O}), 2219(\mathrm{CN}), 2990$ (CH, str.), 3096 (=CH, str.); ${ }^{1} \mathrm{H} \mathrm{NMR}\left(500 \mathrm{MHz}, \mathrm{CDCl}_{3}\right) \delta 1.46$ $\left(\mathrm{CH}_{3}, \mathrm{t}, 3 \mathrm{H}, J=7.2 \mathrm{~Hz}\right), 4.46\left(\mathrm{CH}_{2}, \mathrm{q}, 2 \mathrm{H}, J=7.2 \mathrm{~Hz}\right), 8.17$ (ArH, d, 2H, $J=8.8 \mathrm{~Hz}$ ), 8.34 (=CH, s, 1H) 8.39 (ArH, d, 2H, $J=8.8 \mathrm{~Hz}$ ).

2-Propenoic acid-2-cyano-3-(2-furanyl) ethyl ester (Table 6, Entry 8): White crystall solid, mp $85-87^{\circ} \mathrm{C}$; IR $\left(\mathrm{KBr}, \mathrm{cm}^{-1}\right)$ : 1460, $1622(\mathrm{C}=\mathrm{C}$, aromatic), $1722(\mathrm{C}=\mathrm{O}), 2219(\mathrm{CN}), 2990(\mathrm{CH}$, str.), 3034 (=CH, str.), 3133 (CH, str, aromatic); ${ }^{1} \mathrm{H}$ NMR (500 $\left.\mathrm{MHz}, \mathrm{CDCl}_{3}\right) \delta 1.40\left(\mathrm{CH}_{3}, \mathrm{t}, 3 \mathrm{H}, J=7.2 \mathrm{~Hz}\right), 4.38\left(\mathrm{CH}_{2}, \mathrm{q}, 2 \mathrm{H}\right.$, $J=7.1 \mathrm{~Hz}), 6.68(\mathrm{ArH}, \mathrm{q}, 1 \mathrm{H}, J=1.2 \mathrm{~Hz}), 7.41(\mathrm{ArH}, \mathrm{d}, 1 \mathrm{H}$, $J=3.6 \mathrm{~Hz}$ ), 7.77 (ArH, d, 1H, $J=1.5 \mathrm{~Hz}), 8.03(=\mathrm{CH}, \mathrm{s}, 1 \mathrm{H})$; ${ }^{13} \mathrm{C} \mathrm{NMR}\left(125 \mathrm{MHz}, \mathrm{CDCl}_{3}\right) \delta 14.58\left(\mathrm{CH}_{3}\right), 62.99\left(\mathrm{O}-\mathrm{CH}_{2}\right)$, $99.08(\mathrm{C}-\mathrm{CN}), 122.14(\mathrm{CN}), 114.28,115.75,139.88,148.69$, $149.17,163(\mathrm{C}=\mathrm{O})$.

\section{Results and Discussion}

Reaction process to prepare catalyst P4MVPH/SBA-15. After hybridization of P4VP with SBA-15 by in situ polymerization, P4VP/SBA-15 was obtained. Further, P4VP/SBA-15 was quaternized by methyl iodide and the P4MVPI/SBA-15 was achieved. Finally, P4MVPH/SBA-15 was prepared with anion exchange of iodide by hydroxide in P4MVPI/SBA-15. The procedure for preparing $\mathrm{P} 4 \mathrm{MVPH} / \mathrm{SBA}-15$ is given in Scheme 1.

Characterization of the catalyst. Fig. 1 shows the FT-IR spectra of mesoporous silica SBA-15, P4VP, P4VP/SBA-15 and P4MVPI as well as P4MVPH/SBA-15. The characteristic band at $1050-1080 \mathrm{~cm}^{-1}$ was due to the $\mathrm{Si}-\mathrm{O}$ stretching in $\mathrm{Si}-\mathrm{O}-\mathrm{Si}$ structure, which is seen in the Fig. 1a, c, d, e. In the FT-IR spectrum of P4VP/SBA-15 (Fig. 1c), the new bands at 1602, 


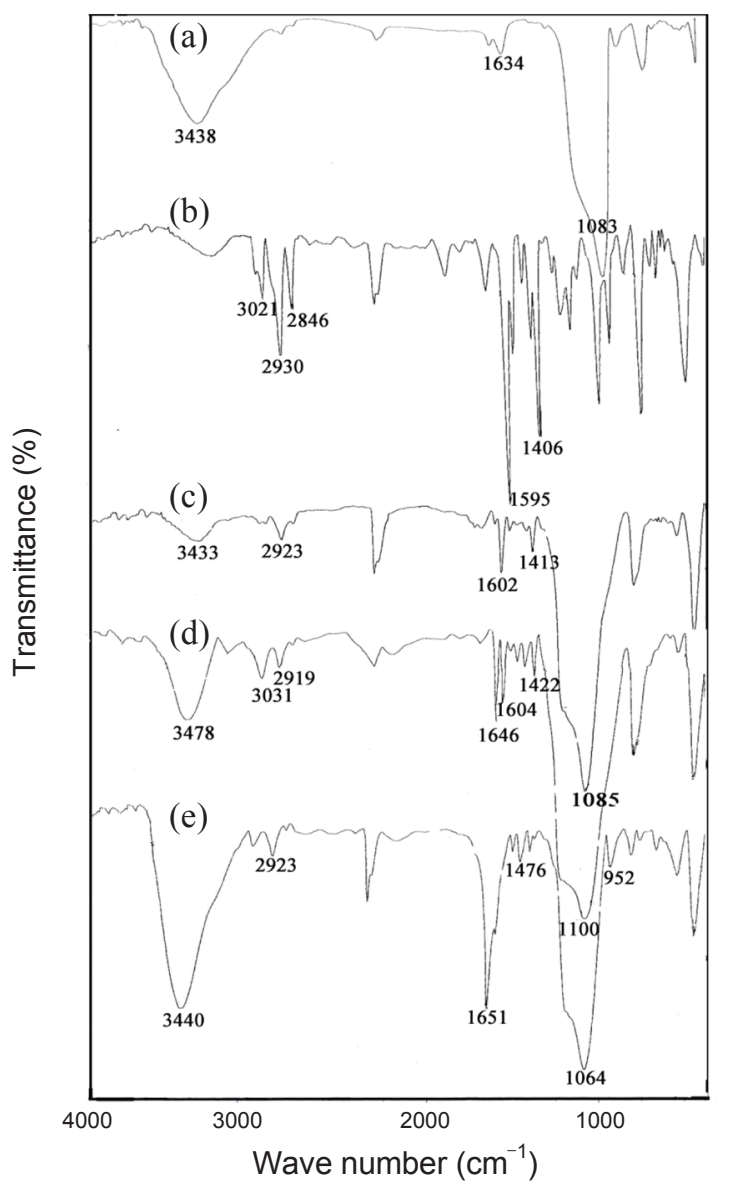

Figure 1. FTIR spectra of (a) mesoporous silica SBA-15, (b) P4VP, (c) P4VP/SBA-15, (d) P4MVPI and (d) P4MVPH/SBA-15.

1558,1496 and $1412 \mathrm{~cm}^{-1}$ were the characteristic absorptions of pyridine ring. Among them the band appeared at $1602 \mathrm{~cm}^{-1}$ was the stretching vibration absorption of $\mathrm{C}-\mathrm{N}$ bond and the bands at 1558,1496 and $1415 \mathrm{~cm}^{-1}$ were attributed to the stretching vibration absorption of $\mathrm{C}=\mathrm{C}$ bond. Moreover, the presence of peaks at around $2800-3050 \mathrm{~cm}^{-1}$ corresponded to the aromatic and aliphatic $\mathrm{C}-\mathrm{H}$ stretching in $\mathrm{P} 4 \mathrm{VP} / \mathrm{SBA}-15$ and the vibration at $856 \mathrm{~cm}^{-1}$ was for $\mathrm{C}-\mathrm{H}$ deformation out of plane. These are consistent with the spectrum of P4VP (Fig. 1b).

The appearance of the above bands shows that P4VP has attached on the surface of SBA-15 and the P4VP/SBA- 15 is obtained. In the spectra of P4MVPI/SBA-15 and P4MVPH/ SBA-15 (Fig. 1d, e), a new peak appears at $1640 \mathrm{~cm}^{-1}$ which is ascribed to the $\mathrm{C}-\mathrm{N}$ ( $\mathrm{CH}_{3}$-pyridinium) bond absorption. This observation confirms the $\mathrm{N}$-alkylation of pyridine ring. In the FT-IR spectrum of P4MVPH/SBA-15 (Fig. 1e), peak at 3450 $\mathrm{cm}^{-1}$ is stronger than the other spectra, in which it is shown the stretching vibration of $\mathrm{OH}$ groups. Furthermore, it is seen $\mathrm{OH}$ bending characteristic at 1651 and $952 \mathrm{~cm}^{-1}$. The appearance of these bands suggests that the exchange between $\mathrm{OH}^{-}$and $\mathrm{I}^{-}$ groups on P4MVPI/SBA-15 occurred and the modified particles P4MVPH/SBA-15 formed.

The powder XRD pattern for mesoporous silica SBA-15 and P4MVPH/SBA-15 is shown in Fig. 2. Typically the low angle diffraction pattern shows evidence of three reflections

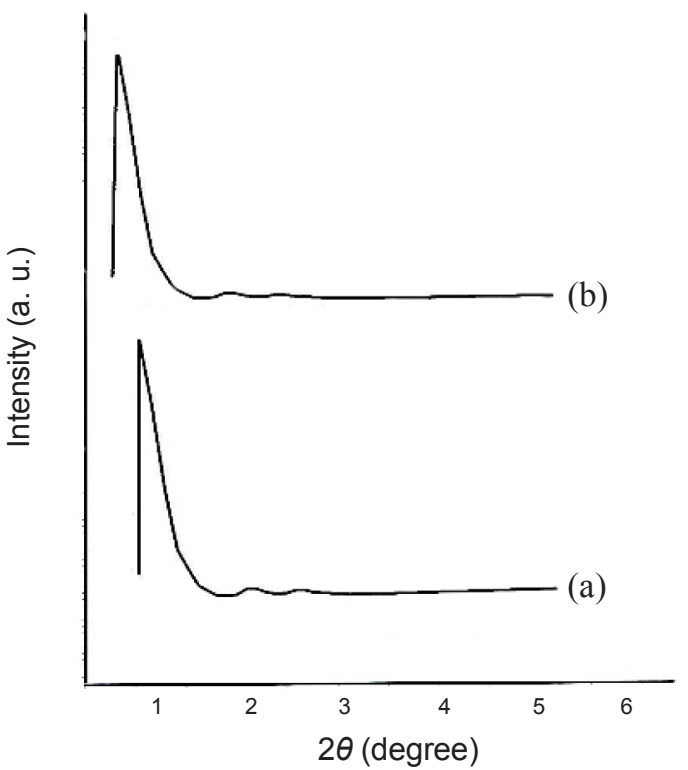

Figure 2. The powder XRD pattern of (a) mesoporous silica SBA-15 and (b) P4MVPH/SBA-15.

at $2 \theta$ values of $0.5^{\circ}-3^{\circ}$, including one strong peak (100), two weak peaks (110) and (200), corresponding to a highly ordered hexagonal mesoporous silica framework. ${ }^{26}$ The P4MVPH/ SBA-15 sample showed the same pattern, indicating that the long-range order of the SBA-15 framework was well retained after immobilizing. However, the intensity of the characteristic reflection peaks of $\mathrm{P} 4 \mathrm{MVPH} / \mathrm{SBA}-15$ sample is found to be reduced, indicating the loss of long-range order. This may be attributed to the symmetry destroyed by the hybridization of SBA-15 which was also found in the ordered mesoporous silica loading with guest matter. In addition, composite contains much less SBA-15 due to the dilution of the silicious material by $\mathrm{P} 4 \mathrm{VP}$, therefore this dilution can also account for a decrease in the peak intensity. Furthermore, the prominent peak (100) of P4MVPH/SBA-15 sample shifts to lower angles compared with mesoporous silica SBA-15.

The $\mathrm{N}_{2}$ adsorption-desorption isotherm of pure SBA-15 and hybrid P4MVPH/SBA-15 samples are shown in Fig. 3. The isotherm was similar to the Type IV isotherm with H1-type hysteresis loops at high relative pressure according to the IUPAC classification, characteristic of mesoporous materials with highly uniform size distributions. Among two branches of adsorptiondesorption isotherms, the presence of a sharp adsorption step in the $\mathrm{P} / \mathrm{P} 0$ region from $0.6-0.8$ and a hysteresis loop at the relative pressure $\mathrm{P} / \mathrm{P}_{0}>0.7$ show that the materials make process a well defined array of regular mesoporous. The specific area and the pore size had been calculated using BrunauerEmmett-Teller (BET) and Barrett-Joyner-Halenda (BJH) methods respectively. The structure data of all these mesoporous materials (BET surface area, total pore volume, and pore size, etc.) were summarized in Table 1. It was known that calcined SBA-15 had a high BET surface area $\left(1430 \mathrm{~m}^{2} / \mathrm{g}\right)$, a large pore volume $\left(1.9 \mathrm{~cm}^{3} / \mathrm{g}\right)$ and pore size $(9.9 \mathrm{~nm})$, indicating its potential application as a host in organic materials. After hybridization with P4VP through in situ polymerization and quaternized with 


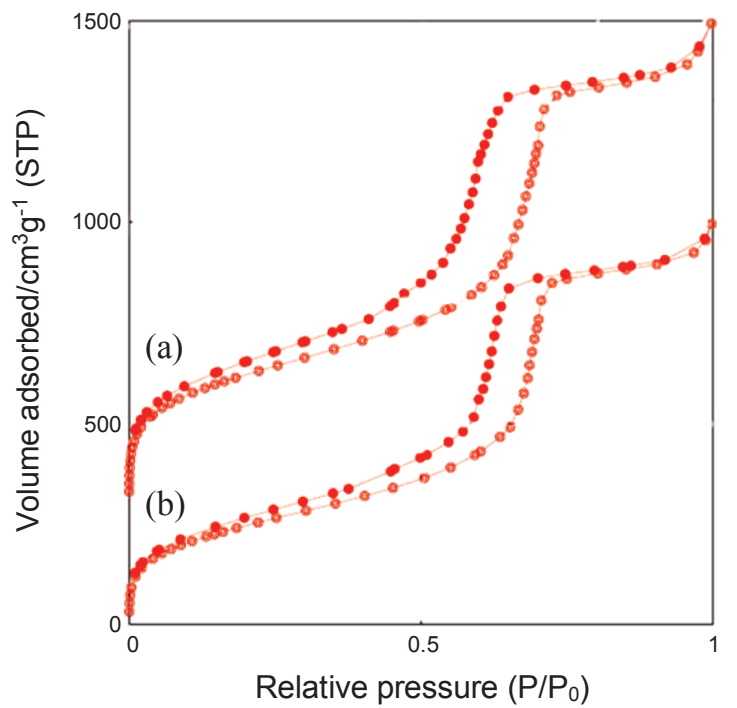

Figure 3. The $\mathrm{N}_{2}$ adsorption-desorption isotherm of (a) pure SBA-15 and (b) P4MVPH/SBA-15.

Table 1. Porosity data of mesoporous silica SBA-15 and P4MVPH/ SBA-15 samples

\begin{tabular}{cccc}
\hline Sample & $\begin{array}{c}\text { BET surface area } \\
\left(\mathrm{m}^{2} \mathrm{~g}^{-1}\right)\end{array}$ & $\begin{array}{c}\mathrm{V}_{\mathrm{P}} \\
\left(\mathrm{cm}^{3} \mathrm{~g}^{-1}\right)\end{array}$ & $\begin{array}{c}\mathrm{D}_{\mathrm{P}} \\
(\mathrm{nm})\end{array}$ \\
\hline $\begin{array}{c}\text { Mesoporous silica SBA-15 } \\
\text { P4MVPH/SBA-15 }\end{array}$ & $\begin{array}{c}1430 \\
906\end{array}$ & 1.90 & 9.90 \\
\hline
\end{tabular}

methyl iodide and then anion exchange, P4MVPH/SBA-15 exhibited a smaller specific area, pore size and pore volume in comparison with those of pure SBA-15, which might be due to the presence of polymer on the surface of the SBA-15. ${ }^{31} \mathrm{Al}-$ though these textural properties are smaller than those found for mesoporous silica SBA-15, P4MVPH/SBA-15 has still mesoporous form and does not block the pores of the SBA-15. As a result, it was suitable to act as a basic catalyst for Knoevenagel condensation.

Fig. 4 gives the scanning electron microscopy (SEM) photographs of SBA-15 and P4MVPH/SBA-15. It is obvious that the surface of SBA-15 is somewhat coarse and irregular before hybridization, whereas the surface of SBA- 15 becomes smooth after hybridization. This results show that the surfaces of SBA15 are filled with P4MVPH.

Fig. 5 shows the TGA curves of P4MVPH and P4MVPH/ SBA-15 under $\mathrm{N}_{2}$ atmosphere. The weight loss (around 55\%, $\mathrm{w} / \mathrm{w}$ ) of P4MVPH began at $260^{\circ} \mathrm{C}$ because of thermo-degradation of P4VPH polymer chains and the degradation ended at $435{ }^{\circ} \mathrm{C}$ (Fig. 5b); whereas for P4MVPH/SBA-15 sample two separate weight loss steps are seen (Fig. 5a). The first (around $11 \%, \mathrm{w} / \mathrm{w}$ ) step appearing at temperature $<150{ }^{\circ} \mathrm{C}$ corresponded to the loss of water (i.e., adsorbed water on the inner and outer surfaces of SBA-15). The second weight loss (about $\left.330-550{ }^{\circ} \mathrm{C}\right)$ amounts around $30 \%(\mathrm{w} / \mathrm{w})$ was related to the degradation of the polymer. Obviously, the hybrid P4MVPH/ SBA-15 had higher thermal stability and slower degradation rate than P4MVPH. Therefore, this was very important for the catalyst application that the thermal stability was enhanced
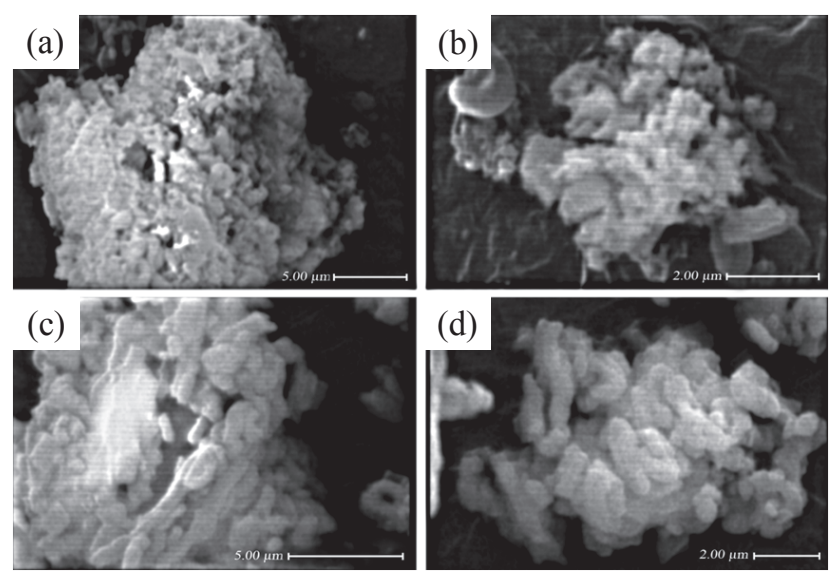

Figure 4. Scanning electron microscopy (SEM) photographs of ( $a, b)$ SBA-15 and (c,d) P4MVPH/SBA-15.

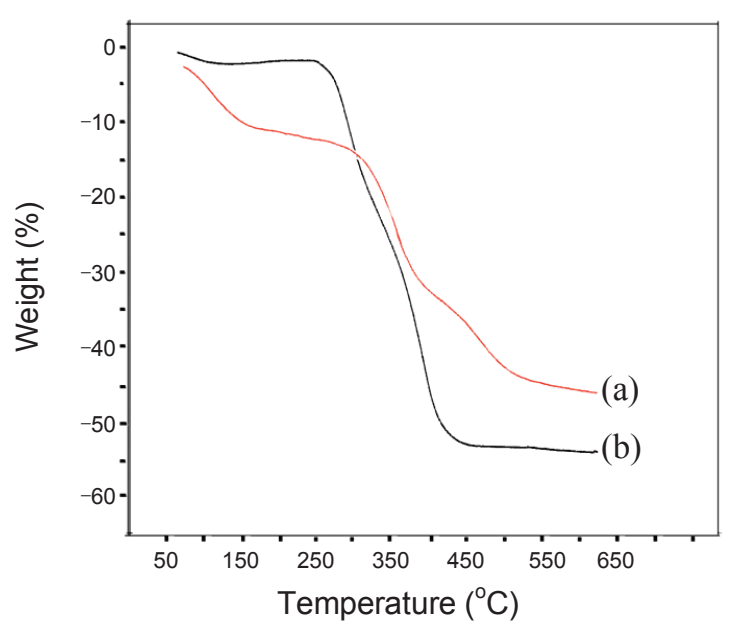

Figure 5. TGA curves of (a) P4MVPH/SBA-15 and (b) P4MVPH.

greatly after hybridization.

The formation of P4MVPH/SBA-15 has been proved by FTIR, TG and BET techniques. FTIR spectrum of this composite shows characterization bands of SBA-15 and P4MVPH. TG thermogram revealed that P4MVPH/SBA-15 showed higher thermal stability than P4MVPH. So this was another reason for composite formation. According to BET results, it was seen that the surface area of SBA- 15 decreased after hybridization with P4MVPH that was indicated interaction of P4MVPH with surface of SBA-15. Whereas SBA-15 had a mesoporous structure, polymerization could occur in the pore of SBA- 15 as well as external surfaces. The data of pore volume and pore diameter proved this fact. Although P4MVPH/SBA-15 textural properties were smaller than those found for mesoporous silica SBA-15, P4MVPH/SBA-15 had still as a mesoporous form (see Fig. 3b) and this isotherm was similar to the Type IV isotherm with H1-type hysteresis loops at high relative pressure according to the IUPAC classification, characteristic of mesoporous materials with highly uniform size distributions. However, after hybridization, the surface area was decreased $37 \%$ and changed into $906 \mathrm{~cm}^{3} / \mathrm{g}$ as a high surface area so that it couldn't be concluded blockage of the SBA-15 pores. 
Other result that proved the formation of composite was amount of polymer leaching from the surface of the SBA- 15 . The leaching of the polymer was determined by washing the composite with methanol, THF and water, repeatedly. Then the amount of polymer was determined in the solution. Our results showed that the leaching of polymer was lower than $10 \%$ and this observation showed that the polymer adsorbed on the surface of the catalyst and so proved the formation of composite.

Catalytic activity. This novel composite was synthesized and fully characterized with different methods. The main goal of this catalytic synthesis was to compare this organic-inorganic composite with other functional polymeric materials and to expand the use of these types of composites for organic reactions. In order to investigate the basic properties of this catalyst the Knoevenagel condensation was chosen as a typical reaction. The effect of different parameters on Knoevenagel condensation of benzaldehyde with ethyl cyanoacetate was investigated and the results are as follows.

Effect of solvent: In case of heterogeneous basic catalysts, the character of the solvent used may have a strong effect on the reaction rate due to polarity characteristics. As usual, the higher the polarity, the faster the reaction rate. ${ }^{5,22}$ This behavior was attributed to the influence of the solvent on the transition state and to a change in the capacity of the catalyst for proton transfer: when polar reagents were involved, the transition-state complex was better solvated by polar solvents and the partition of the reactants at the solid-liquid interface was higher, decreasing the activation free enthalpy and enhancing the reaction rate.

The influence of the solvent on the reaction rate of benzaldehyde and ethyl cyanoacetate catalyzed by P4MVPH/SBA-15 was investigated for solvents with different dielectric constants $(\varepsilon)$ and amphiprotic properties: acetonitrile $(\varepsilon=36.6)$, tetrahydrofuran $(\varepsilon=7.52)$, ethanol $(\varepsilon=24.3)$, cyclohexane $(\varepsilon=$ $2.05)$, toluene $(\varepsilon=2.4)$, dichloromethane $(\varepsilon=9.1), \mathrm{H}_{2} \mathrm{O}(\varepsilon=$ $78.5)$, and solvent-free conditions. The dielectric constant could be considered as a measure of polarity. Results are shown in Table 2. The highest yield was obtained using water as solvent, so $\mathrm{H}_{2} \mathrm{O}$ proved to be the most active solvent for the reaction. The salvation energy was decreased with increasing the polarity of the solvent. This clearly indicated that the reactants, intermediates and products were more stabilized when polarity of solvent were increased. Because of the polar nature of this catalyst, water showed the best results for this reaction as a solvent. In addition, ethanol was used for products work-up. So it could be assumed that this reaction was green and classified under environmental-friendly reaction.

It should be mentioned that both reagents were insoluble in water under the experimental conditions and there were two phases at the beginning and also during the reaction. Because of amphiphilic nature of the catalyst, hydrophobic reagents could be absorbed on the surface of the catalyst and the reaction could proceed at this surface. In other word, for these systems, a model proposed was that the reaction actually performed on the surface of the catalyst. It should be mentioned that the reaction mixture should be stirred vigorously (mild stirring rate, results in relatively low yield). In this condition, the reagents could be adsorbed and reacted with each other on the surface of the
Table 2. Effect of solvent on Knoevenagel condensation

\begin{tabular}{|c|c|c|}
\hline Solvent & Time (min) & Yield $^{a}(\%)$ \\
\hline Water & 10 & 98 \\
\hline Toluene & $\begin{array}{c}10 \\
120^{b}\end{array}$ & $\begin{array}{l}33 \\
82\end{array}$ \\
\hline Ethanol & $\begin{array}{c}10 \\
120^{b}\end{array}$ & $\begin{array}{l}74 \\
74\end{array}$ \\
\hline Acetonitrile & $\begin{array}{c}10 \\
120^{b}\end{array}$ & $\begin{array}{l}21 \\
20\end{array}$ \\
\hline Tetrahydrofuran & $\begin{array}{c}10 \\
120^{b}\end{array}$ & $\begin{array}{c}\text { NR } \\
15\end{array}$ \\
\hline Dichloromethane & $\begin{array}{c}10 \\
120^{b}\end{array}$ & $\begin{array}{l}\text { NR } \\
\text { NR }\end{array}$ \\
\hline Solvent-free & $\begin{array}{c}10 \\
120^{b}\end{array}$ & $\begin{array}{l}37 \\
89\end{array}$ \\
\hline
\end{tabular}

Reaction conditions: P4MVPH/SBA-15 (0.12 g), benzaldehyde ( $2 \mathrm{mmol})$, ethyl cyanoacetate $(2 \mathrm{mmol})$, solvent $(10 \mathrm{~mL})$, reflux. ${ }^{a}$ Isolated yield. ${ }^{b}$ Time of maximum yield.

Table 3. Effect of temperature on Knoevenagel condensation

\begin{tabular}{ccc}
\hline Temperature & Time $(\mathrm{min})$ & Yield $^{a}(\%)$ \\
\hline \multirow{2}{*}{$25^{\circ} \mathrm{C}(\mathrm{rt})$} & 10 & 29 \\
& $60-120^{b}$ & 90 \\
$40{ }^{\circ} \mathrm{C}$ & 10 & 48 \\
& $60-120^{b}$ & 91 \\
\multirow{2}{*}{$60^{\circ} \mathrm{C}$} & 10 & 77 \\
& $30^{b}$ & 95 \\
$80{ }^{\circ} \mathrm{C}$ & 10 & 86 \\
& $20^{b}$ & 98 \\
\hline $95^{\circ} \mathrm{C}$ (reflux) & 10 & 98 \\
\hline
\end{tabular}

Reaction conditions: benzaldehyde ( $2 \mathrm{mmol})$, ethyl cyanoacetate, $(2 \mathrm{mmol})$, catalyst $(0.12 \mathrm{~g}), \mathrm{H}_{2} \mathrm{O}(10 \mathrm{~mL}){ }^{a}$ Isolated yield. ${ }^{b}$ Time of maximum yield.

catalyst.

Effect of reaction temperature: The effect of reaction temperature on the Knoevenagel condensation was studied in the range of $25{ }^{\circ} \mathrm{C}-95{ }^{\circ} \mathrm{C}$ (reflux) in water by keeping other reaction parameters constant. Experimental results are shown in Table 3 . The yield was increased from $90 \%$ to $98 \%$ by increasing the temperature from $25{ }^{\circ} \mathrm{C}$ to $95{ }^{\circ} \mathrm{C}$. Also by increasing the temperature the duration of reaction was decreased from 120 to $10 \mathrm{~min}$. Thus, $95^{\circ} \mathrm{C}$ (reflux) was considered as an optimum reaction temperature.

Effect of SBA-15 amount on the catalytic activity of P4MVPH/SBA-15 composite: One of the greatest advantages of this catalyst was to easily use due to its powdery structure. P4MVPH was adhesive and this character made it hard to separate it from the vessel; but after mixing with SBA-15 and making P4MVPH/ SBA-15 composite, it becomes powdery which was easily to be used and recycled. Also comparative reaction by using P4MVPH and P4MVPH/SBA-15 showed that P4MVPH/SBA15 was more efficient, by completion the reaction in a short time. On the other hand, the yield was decreased and the reaction was carried out in a long period of time using P4MVPH. On the basis of the turnover frequency (TOF) defined in Table 4, 
Table 4. Effect of SBA-15 amount on catalytic activity of composite P4MVPH/SBA-15

\begin{tabular}{|c|c|c|c|c|c|}
\hline Entry & Amount of SBA-15/4VP $(\mathrm{g} / \mathrm{mL})$ & Time (min) & Yield $^{a}(\%)$ & TOF $\left(\mathrm{h}^{-1}\right)^{b}$ & BET surface area $\left(\mathrm{m}^{2} \mathrm{~g}^{-1}\right)$ \\
\hline 1 & $0 / 0.5$ & 20 & 79 & 2.1 & - \\
\hline 2 & $0.25 / 0.5$ & 10 & 76 & 17.8 & 783 \\
\hline 3 & $0.5 / 0.5$ & 10 & 98 & 19.1 & 906 \\
\hline 4 & $1.0 / 0.5$ & 40 & 81 & 6.0 & 1170 \\
\hline 5 & $0.5 / 0$ & 120 & 0 & 0 & 1430 \\
\hline
\end{tabular}

Reaction conditions: benzaldehyde $(2 \mathrm{mmol})$, ethyl cyanoacetate $(2 \mathrm{mmol})$, catalyst $(0.12 \mathrm{~g}), \mathrm{H}_{2} \mathrm{O}(10 \mathrm{~mL}), 95{ }^{\circ} \mathrm{C} .{ }^{a}$ Isolated yield. ${ }^{b}$ Moles of product per mol of catalyst per hour.

it was obvious that composite P4MVPH/SBA-15 systems (entry $2,3,4)$ were advantageous. In fact, the activity of P4MVPH was much lower than those of P4MVPH/SBA-15 with various ratios of polymer to SBA-15 (entry 2,3,4). These results were due to the large surface area of $\mathrm{P} 4 \mathrm{MVPH} / \mathrm{SBA}-15$ in comparison with P4MVPH.

In order to investigate the effect of SBA-15 on catalytic activity, different kinds of $\mathrm{P} 4 \mathrm{MVPH} / \mathrm{SBA}-15$ catalysts in which the amount of the SBA-15 were $0.0,0.25,0.5$ and $1 \mathrm{~g}$, for polymerization of $0.5 \mathrm{~mL} 4 \mathrm{VP}$ respectively, prepared and used in the Knoevenagel condensation. Table 4 displays the experimental results. The best result was obtained when ratio of SBA-15 (g) to 4VP (mL) was 1:1. Obviously, the greater amount of the SBA-15 did not lead to the higher catalytic activity of the P4MVPH/SBA-15 as a catalyst. It should be noticed that when SBA-15 used as a catalyst, the reaction did not proceed significantly.

According to Agarwal and Titman report, a possible adsorption mode for $\mathrm{P} 4 \mathrm{VP} /$ silica was a lone pair interaction between the pyridine nitrogen atom and the hydroxyl protons on the silica surface. ${ }^{32}$ An alternative would be involved with the pyridine ring. Other interactions would be an interaction involving the pyridine ring л-interaction or a less specific Van Der Waals interaction between the aliphatic polymer chain backbone and the silica surface. Two of these possibilities were illustrated schematically in Scheme 2. They were used in high-resolution proton carbon-13 and proton-silicon-29 correlation experiments in combination to assign the proton resonances in the composites, using the original silica sols and the P4VP. Their experiments proved the interactions mentioned above. So according to similar structure for SBA-15, these interactions could be proposed for interaction of SBA-15 and P4VP.

In order to determine the ratio of pyridine and pyridinium in P4MVPH/SBA-15, we used two methods. First, gravimetric data shows that $3.9 \mathrm{mmol}$ of pyridine existed per gram of $\mathrm{P} 4 \mathrm{VP} /$ SBA-15 composite and $1.3 \mathrm{mmol}$ of methyl iodide existed per gram of P4MVPI/SBA-15. So about $66 \%$ of pyridine groups of composite were free and $33 \%$ of pyridine groups were quaternized by methyl groups. Another technique was ICP-mass. The samples were analyzed and the average iodide content was determined to be $1.5 \mathrm{mmol} \mathrm{g}^{-1}$ by this method.

According to the above results, amount of $4 \mathrm{VP}$ played an important role in the formation of composite. With increasing the amount of 4VP, the formation of P4VP and also the molecular weight of P4VP increased. So, the active surface of SBA-15 was more occupied and also the amount of polymer on the internal pores of SBA-15 increased. Therefore, we could see that

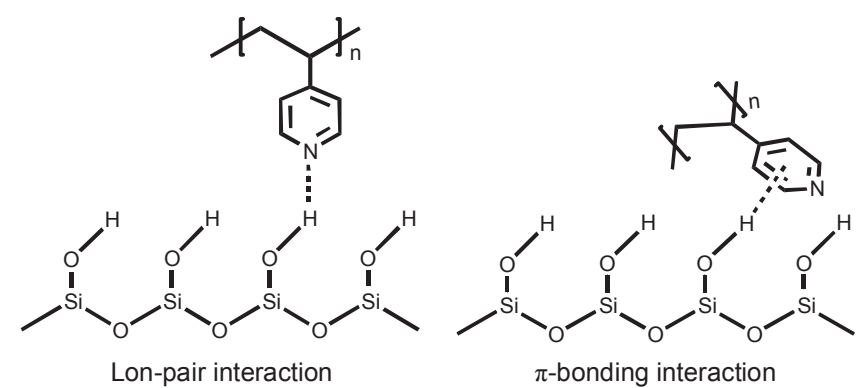

Scheme 2. Schematic representation of P4MVPH interaction with SBA-15

the polymers, block some pores of the catalyst and the surface area of the catalyst were decreased with increases the ratio of 4VP (mL) to SBA-15 (g) (Table 4, entry 2). Therefore, TOF was lower for P4MVPH/SBA-15 when the ratio of $4 \mathrm{VP}(\mathrm{mL})$ to SBA-15 (g) was 0.5:0.25 than that of P4MVPH/SBA-15 when the ratio of 4VP $(\mathrm{mL})$ to SBA-15 (g) was 0.5:0.5 (Table 4, entry 2,3 ). So the amount of $4 \mathrm{VP}$ for preparation of composite had a critical role.

It should be mentioned that the amount of the initiator (benzoylperoxide) was important for preparation of the composite. Because the amount of benzoylperoxide could effect on the polymer chains and molecular weight of polymer, so various amounts of benzoylperoxide was used for composite preparation and the best results was found to be $3 \mathrm{wt} \%$.

Effect of the amount of catalyst P4MVPH/SBA-15 on the catalytic Knoevenagel condensation: In the reaction system containing benzaldehyde ( $2 \mathrm{mmol}$ ), ethylcyanoacetate $(2 \mathrm{mmol})$, $\mathrm{H}_{2} \mathrm{O}(10 \mathrm{~mL})$ and catalyst, the Knoevenagel condensation were carried out at $95^{\circ} \mathrm{C}$ with different amounts of the catalyst added. In Fig. 6 it is shown that the higher amounts of catalyst $(0.12 \mathrm{~g}$

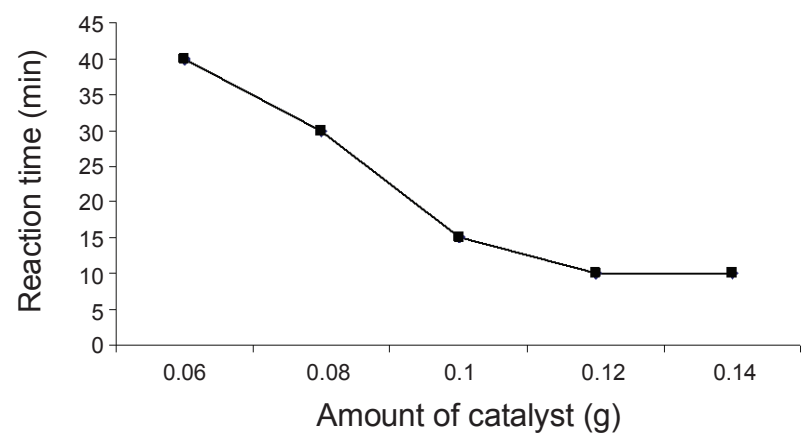

Figure 6. Effect of the amount of catalyst P4MVPH/SBA-15 on the catalytic Knoevenagel condensation. 
and $0.14 \mathrm{~g}$ ) had no appreciable effect on the yield (the yield is $98 \%$ in all cases) and duration of reaction. But when the catalyst amount decreased from 0.12 to $0.06 \mathrm{~g}$, the duration of reaction were increased from 10 to $40 \mathrm{~min}$. So it could be considered that $0.12 \mathrm{~g}$ is a suitable amount of used (P4MVPH/SBA-15) catalyst for the reaction system, above described.

Effect of alkyl chain length on the catalytic activity: Different catalysts with variable length of alkyl chain on the pyridinium were prepared. Interestingly, as to the catalyst with variable length of alkyl chain on the pyridinium moiety, we found that the activity decreased, though slightly but gradually in the sequence of $\mathrm{CH}_{3}>\mathrm{C}_{4} \mathrm{H}_{9}>\mathrm{C}_{5} \mathrm{H}_{11}$, which could be ascribed to the low accessibility to the basic centers with increase of steric hindrance as well as the less loading basic centers (Table 5).

Application of P4MVPH/SBA-15 in Knoevenagel condensation of various aldehydes with ethylcyanoacetate: The catalytic activity of P4MVPH/SBA-15 was investigated for the Knoevenagel condensation by employing various aromatic and hetero-aromatic aldehydes with ethylcyanoacetate as an active methylene compound (Scheme 3 ). All reactions were almost completed in 5 - $30 \mathrm{~min}$ in refluxing water as solvent (Table 6). These reactions produced the corresponding electrophilic alkenes in high yield with $100 \%$ selectivity to the condensation products. Also no Micheal additional product was observed. Hetero-aromatic aldehydes, such as 2-pyridine carbaldehyde
Table 5. Effect of alkyl halides length on the catalytic activity of P4MVPH/SBA-15 catalyzed Knoevenagel condensation

\begin{tabular}{cccc}
\hline alkyl chain & catalyst & $\begin{array}{c}\text { Time } \\
(\mathrm{min})\end{array}$ & $\begin{array}{c}\text { Yield }^{a} \\
(\%)\end{array}$ \\
\hline Methyl & P4MVPH/SBA-15 & 10 & 98 \\
Butyl & P4BVPH/SBA-15 & 10 & 79 \\
& & $20^{c}$ & 98 \\
\hline \multirow{2}{*}{ Pentyl } & P4PVPH/SBA-15 & 10 & 68 \\
& & $40^{e}$ & 98 \\
\hline
\end{tabular}

Reaction conditions: benzaldehyde ( $2 \mathrm{mmol})$, ethylcyanoacetate $(2 \mathrm{mmol})$, catalyst $(0.12 \mathrm{~g}), \mathrm{H}_{2} \mathrm{O}(10 \mathrm{~mL}), 95^{\circ} \mathrm{C}$. Isolated yield. ${ }^{b}$ poly(4-methyl vinylpyridinium hydroxide)/SBA-15. ${ }^{c}$ poly(4-butyl vinylpyridinium hydroxide)/ SBA-15. ${ }^{d}$ poly(4-pentyl vinylpyridinium hydroxide)/SBA-15. ${ }^{e}$ Time of maximum yield.

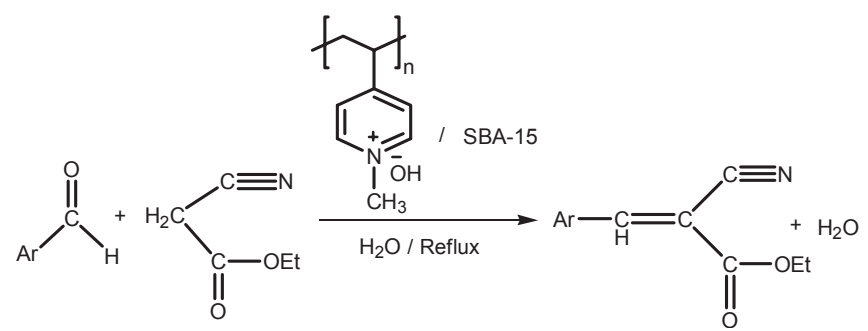

Scheme 3. Knoevenagel condensation catalyzed by P4MVPH/SBA-15

Table 6. Knoevenagel condensation reaction of aromatic aldehydes and ethyl cyanoacetate catalyzed by P4MVPH/SBA-15

\begin{tabular}{|c|c|c|c|c|c|c|c|}
\hline \multirow{2}{*}{ Entry } & \multirow{2}{*}{ Substrate } & \multirow{2}{*}{ Product } & \multirow{2}{*}{ Time (min) } & \multirow{2}{*}{ Yield $^{a}(\%)$} & \multicolumn{2}{|c|}{$m p\left({ }^{\circ} \mathrm{C}\right)$} & \multirow{2}{*}{ Ref. } \\
\hline & & & & & Found & Reported & \\
\hline 1 & & & 10 & 98 & $49-51$ & 50 & 33 \\
\hline 2 & & & 5 & 99 & $92-94$ & $95-96$ & 34 \\
\hline 3 & & & 35 & 96 & $82-85$ & Not reported & This work \\
\hline 4 & & & 10 & 84 & $172-174$ & $173-175$ & 35 \\
\hline 5 & & & 15 & 70 & $81-82$ & 80 & 33 \\
\hline 6 & & & 15 & 86 & $52-54$ & $53-54$ & 36 \\
\hline 7 & & & 5 & 98 & 165 & 169 & 33 \\
\hline 8 & & & 15 & 97 & $85-87$ & $89-91$ & 37 \\
\hline
\end{tabular}




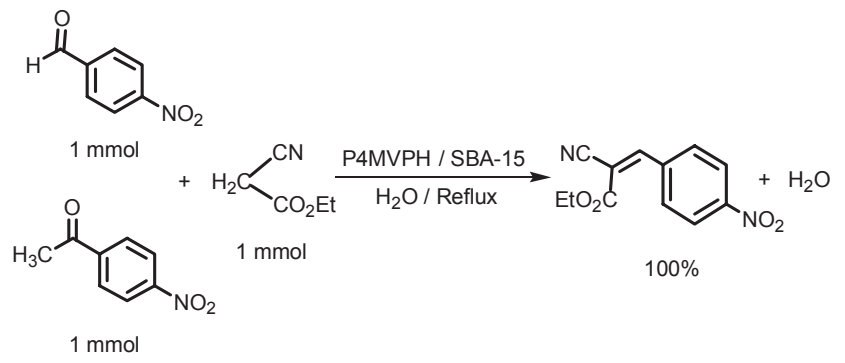

Scheme 4. Chemoselectivity of the catalyst P4MVPH/SBA-15

Table 7. The catalyst reusability

\begin{tabular}{ccc}
\hline Cycle & Time $(\min )$ & Yield $^{a}(\%)$ \\
\hline fresh & 10 & 98 \\
\hline 1 & 10 & 98 \\
\hline 2 & 10 & 98 \\
\hline 3 & 10 & 95 \\
4 & 20 & 96 \\
\hline
\end{tabular}

${ }^{a}$ Isolated yield.

(entry 2) and furfural (entry 8) provided very good yields. Aromatic aldehydes with electron withdrawing groups $\left(-\mathrm{NO}_{2}\right)$ also offered good yields and the reactions were completed in short times (entry 7). Also in the case of electron donating groups $\left(-\mathrm{CH}_{3},-\mathrm{OH},-\mathrm{OCH}_{3}\right)$, reasonably good yields were observed but demanded little more reaction time (entry 3, 4, 5).

Study of the catalyst reusability: The recovered catalyst from the experiment was washed with water $(10 \mathrm{~mL})$ and acetone $(3 \times 5 \mathrm{~mL})$. Then dried in oven at $60{ }^{\circ} \mathrm{C}$ and used in the Knoevenagel condensation. The results showed that this catalyst could be reused without any modification, 4 times and no significant loss of activity/selectivity performance was observed (Table 7). In all cases, reasonably good yields were observed but by using reused catalyst, more reaction time was demanded (entry 3,4$)$.

\section{Conclusion}

In summary, it was demonstrated that P4MVPH/SBA-15 was a novel basic polymeric composite that could behave as recyclable catalyst for the Knoevenagel condensation reaction of aromatic aldehydes with ethyl cyanoacetate at $95{ }^{\circ} \mathrm{C}$ in 5 30 min in $\mathrm{H}_{2} \mathrm{O}$ as a solvent with $100 \%$ selectivity to $\alpha, \beta$-unsaturated carbonyl compounds and offering a good yield and also high chemoselectivity. The existence of both organic and inorganic phase in this composite had the critical effect on the catalytic activity. The merit of this methodology was the simplicity, fast, mild, and efficient. Therefore it is believed that the new synthetic method reported here would greatly contribute to the environmentally greener and safer process.

Acknowledgments. Supported by Islamic Azad University,
Shahreza Branch (IAUSH) Research Council and Center of Excellence in Chemistry which is gratefully acknowledged.

\section{References}

1. Seki, T.; Onaka, M. J. Mol. Catal. A: Chem. 2007, 263, 115.

2. Saravanamurugan, S.; Palanichamy, M.; Hartmann, M.; Murugesan, V. Appl. Catal. A: Gen. 2006, 298, 8.

3. Wirz, R.; Ferri, D.; Baiker, A. Langmuir 2006, 22, 3698.

4. Martin-Aranda, R. M.; Ortega-Cantero, E.; Rojas-Cervantes, M. L.; Vicente-Rodriguez, M. A.; Banares-Munoz, M. A. J. Chem. Technol. Biotechnol. 2005, 80, 234.

5. Climent, M. J.; Corma, A.; Dominguez, I.; Iborra, S.; Sabater, M. J.; Sastre, G. J. Catal. 2007, 246, 136.

6. Rodriguez, I.; Sastre, G.; Corma, A.; Iborra, S. J. Catal. 1999, $183,14$.

7. Jones, G. Org. React. 1967, 15, 204.

8. Lehnert, W. Tet. Lett. 1970, 54, 4723.

9. Cabello, J. A.; Campelo, J. M.; Garcia, A.; Luna, D.; Marina, J. M. J. Org. Chem. 1984, 49, 5195.

10. Shanthan, R. P.; Venkataratnam, R. V. Tet. Lett. 1991, 41, 5821.

11. Bennazha, J.; Zabouily, M.; Sbeti, S.; Boukhari, A.; Holt, E. M. Catal. Commun. 2001, 2, 101.

12. Zhang, M.; Zhang, A. Q.; Tang, X. H. Chin. J. Org. Chem. 2004, $24,1106$.

13. Xu, X. M.; Li, Y. Q.; Zhou, M. Y. Chin. J. Org. Chem. 2004, 24, 1253.

14. Yi, H.; Jue, C.; Zhang, G. L. Synth. Commun. 2005, 35, 739.

15. Chen, X.; Li, X.; Song, H.; Lu, Y.; Wang, F.; Hu, A. Chin. J. Catal. 2008, $29,957$.

16. Zhang, Y.; Zhao, Y.; Xia, C. J. Mol. Catal. A: Chem. 2009, 306, 107.

17. Cai, Y.; Peng, Y.; Song, G. Catal. Lett. 2006, 109, 61.

18. Sheldon, R. A. Pure Appl. Chem. 2000, 72, 1233.

19. Weitkamp, J.; Hunger, M.; Rymsa, U. Micropor. Mesopor. Mater. 2001, 48, 255.

20. Tamami, B.; Fadavi, A. Iranian Poly. J. 2006, 15, 331.

21. Jerome, F.; Kharchafi, G.; Adam, I.; Barrault, J. Green Chem. 2004, 6, 72 .

22. Corma, A.; Iborra, S.; Rodriguez, I.; Sanchez, F. J. Catal. 2002, 211, 208.

23. Corma, A.; Hamid, S. B. A.; Iborra, S.; Velty, A. J. Catal. 2005 , $234,340$.

24. Corma, A. J. Catal. 2003, 216, 298.

25. Zhao, D. Y.; Huo, Q. S.; Feng, J. L.; Chmelka, B. F.; Stucky, G. D. J. Am. Chem. Soc. 1998, 120, 6024.

26. Zhao, D. Y.; Feng, J. L.; Huo, Q. S.; Melosh, N.; Fredrickson, G. H.; Chmelka, B. F.; Stucky, G. D. Science 1998, 279, 548.

27. Králik, M.; Biffis, A. J. Mol. Catal. A: Chem. 2001, 177, 113.

28. Malynych, S.; Luzinov, I.; Chumanov, G. J. Phys. Chem. B 2002, $106,1280$.

29. Tamami, B.; Borujeni, K. P. Iranian Poly. J. 2009, 18, 191.

30. Goettmann, F.; Sanchez, C.; Parvanak Borujeni, K. J. Mater. Chem. 2007, 17, 24.

31. Colilla, M.; Balas, F.; Manzano, M.; Vallet-Regí, M. Chem. Mater. 2007, 19, 3099.

32. Agarwal, G. K.; Titman, J. J.; Percy, M. J.; Armes, S. P. J. Phys. Chem. B 2003, 107, 12497.

33. Kumbhare, R. M.; Sridhar, M. Catal. Commun. 2008, 9, 403.

34. Flitsch, W.; Kahner-Grone, S. Chemische Berichte 1982, $115(3)$, 871.

35. Krishnan, G. R.; Sreekumar, K. Euro. J. Org. Chem. 2008, 4763.

36. Fan, X.; Hu, X.; Zhang, X.; Wang, J. Aust. J. Chem. 2004, 57, 1067.

37. Yadav, J. S.; Reddy, B. V. S.; Basak, A. K.; Visali, B.; Narsaiah, A. V.; Nagaiah, K. Eur. J. Org. Chem. 2004, 546. 